\title{
Why Choosing Healthy Foods is Hard, and How to Help: Presenting the 4Ps Framework for Behavior Change
}

\author{
Zoe Chance • Margarita Gorlin • Ravi Dhar
}

Published online: 12 September 2014

(C) Springer Science+Business Media New York 2014

\begin{abstract}
The pursuit of long-term goals is often thwarted by immediate desires-a pattern particularly common in food choices. Research in economics, psychology, and marketing has identified a rich supply of unrelated small influences or "nudges" that can help make healthy choices easier, aligning behaviors with intentions. We organize these streams of research using a novel taxonomy, the 4Ps Framework for Behavior Change, to integrate nudges within a dual-system model of consumer choice and to provide suggestions for extensions. We conclude with a discussion of some practical challenges facing researchers in this area.
\end{abstract}

Keywords Behavioral economics $\cdot$ Nudges $\cdot$ Food $\cdot$ Health $\cdot$ Dual systems

\section{Introduction}

An implicit assumption of most consumer choice research is that people consciously choose the alternative they prefer: choices reveal underlying preferences [59, 70]. It might at first seem obvious that if you buy and consume a bucket of popcorn at the movies, you must have preferred it to no popcorn, and to all other potential alternatives. However, this inference is questionable for three reasons. First, it assumes you made the popcorn buying and eating decisions mindfully, rather than out of habit. Second, it assumes you were aware of and considered all the potential alternatives - including stopping eating - throughout the process. Third, it suggests that if you held conflicting preferences (e.g., future fitness versus current buttery goodness), your "true" preference won out. In

Z. Chance $(\bowtie) \cdot M$. Gorlin $\cdot$ R. Dhar

Yale School of Management, 165 Whitney Avenue, New Haven, CT 06511, USA

e-mail: zoe.chance@yale.edu this article, we discuss why choices do not necessarily match conscious preferences. Research shows that many behaviors are performed mindlessly [4]_particularly eating [81] —and actions often precede conscious thought $[42,72]$. Even when acting consciously, people often fail to consider all potential options. Finally, while it would be impossible to say which preferences are "truer," the future- or present-oriented ones, multiple factors bias choices toward immediate gratification. There are few domains in which potential conflicts between future- and present-oriented preferences are so salient as in choices between healthy and unhealthy foods.

Most people report a desire to eat healthfully [65], yet eating poorly and too much has contributed to an obesity epidemic in the USA. As Ruhm writes, "there is little indication that the large secular increases in body mass index have been accompanied by a corresponding growth in utilitymaximizing weight" ([58], p. 781). Supporting his claim that "individuals act as if their eating patterns represent mistakes rather than planned behavior" ([58], p. 781), each year, American consumers spend more than US\$50 billion dollars on weight loss attempts [47] —including more than 200,000 bariatric surgeries [24]. Furthermore, obesity has become the leading preventable cause of death. In addition to increasing the personal risks of heart disease, diabetes, and other chronic illnesses [16], obesity is estimated to account for almost $10 \%$ of total annual medical expenditures in the USA [14]. It is therefore in everyone's best interest to help make healthier food choices easier.

In this article, we review research on nudging people toward healthy choices, and offer a framework to support the application and extension of this research. We first describe a dual-system decision making process, with intuitive responses being sometimes overridden by deliberative ones, that helps explain why healthy food choices are difficult to make. Next, we introduce a new framework-the 4Ps Framework for Behavior Change - to propose ways to help 
make healthy choices easier, integrating research findings from behavioral economics, psychology, and marketing. This framework provides many opportunities for nudging people gently toward healthy choices by changing what choices are offered, how choices are made, how choices are communicated, and how intentions are reinforced. In the final section, we discuss some practical challenges of researching how to nudge people toward healthy choices.

\section{System 1 and System 2}

Dual-process models classify cognitive processes into two systems - intuition and reason (cf: $[12,71])$. The intuitive process, known as System 1, is quick and heuristic-based, while the rational process, known as System 2, is deliberate and rule-based [74]. Choices emerge as an interplay between the two systems. System 1 can be thought of as generating a first impression or gut response, with System 2 sometimes second-guessing that response $[35,73]$. While originally the framework was applied to understanding judgments, Dhar and Gorlin [10] extended the dual-system framework to the choice domain: one option in a choice set may elicit a strong System 1 response, while another may require the conscious deliberation of System 2. For example, the immediate urge to grab a doughnut is generated by System 1, whereas contemplating the potential health consequences of eating doughnuts requires engaging System 2.

System 2 does not always monitor the System 1 response carefully for several reasons. First, the two systems often agree. Second, while System 2 is capable of conscious, logical thought, deliberation is effortful, requiring both ability and motivation. Often, ability is limited by multitasking or distractions. Extraneous thoughts compete for attention and siphon away mental processing power, inducing a state called "cognitive load," in which System 2 is less likely to override System 1 responses [67].

In other circumstances, actions are performed "mindlessly," bypassing conscious processing altogether. Although people experience their decisions as willful, researchers find that the choice environment can exert strong unconscious influences. For example, people rarely realize that the amount of food they eat depends on the size of the portion, plate, utensil, or cup - and even the lighting and music (see [81, 82] for reviews of this research). Furthermore, repeated behaviors become habitual, occurring without conscious intent.

We have discovered that the System 1/System 2 framework has important implications in the domain of health choices. To the extent that the intuitive system favors the unhealthy option, decisions become biased toward that option. We discuss next why System 1 tends to favor unhealthy options, and how the food domain offers specific challenges for System 2.

\section{Why Choosing Healthy Foods is Hard}

Whereas there is nothing inherently unique about choices that impact health, there are several psychological factors that make the choice of a healthy option difficult. These choices tend to force tradeoffs between present and future costs and benefits. In particular, whereas most benefits of unhealthy options are certain and immediate, many potential costs are uncertain and far in the future. The reverse is true for healthy options: most costs are certain and immediate, but many potential benefits are uncertain and far in the future [53, 89]. For example, eating buttery popcorn is pleasurable in the moment, whereas indulging frequently in large buckets of buttery popcorn could lead to weight gain and health problems - but these outcomes are uncertain and far in the future.

First, choosing between a certain and immediate pleasure and an uncertain future cost is intellectually challenging. System 1 is wired to respond to immediate pleasure by producing a feeling of desire. In order to consider discount rates and weigh more abstract future outcomes, the decision maker must engage System 2 and make multiple probabilistic assumptions. That reasoning task is effortful and complex. As a result, System 2 often fails, leaving decisions biased toward the unhealthy options favored by System 1.

Second, even when System 2 is engaged, excessive discounting of future outcomes exacerbates the difficulty of weighing tradeoffs [17]. People tend to be present-biased: they overemphasize immediate benefits and costs and undervalue costs and benefits that are delayed $[1,17,55,56]$. Again, this bias results in favoring unhealthy options which appeal to System 1.

Third, unhealthy behaviors carry a substantial cost only if they are regularly repeated. Since the long-term cost of any one food decision is negligible, people tend to underestimate the cost of choosing unhealthy foods because they fail to aggregate over consumption episodes, treating each consumption occasion as separate and neglible [38]. Even worse, when people do consider consumption in aggregate, they are motivated to believe they will make healthier choices in the future [37] and therefore feel licensed to make an indulgent choice now $[15,36]$.

A fourth special challenge of health choices is the requirement for self-control. Even when deliberation has declared the unhealthy choice "wrong," resisting the temptation still requires self-control. Self-control is the capacity to alter behavior in the pursuit of personal long-term goals - and this capacity is limited. Researchers have found that resisting one impulse diminishes the ability to resist the next, a phenomenon known as depletion [5, 61]. Decision makers have particular trouble exerting self-control when they are tired, stressed, sick, under time pressure - or hungry [61, 80]. Thus, selfcontrol is likely to be depleted in the context of health decisions, particularly food choices. 
A final challenge is that health choices are often made with little conscious deliberation [94]. People make over 200 foodrelated decisions per day, yet recall making only fifteen [86]. Many food decisions are habitual: a frequently performed behavior can become encoded as a context-response pattern in memory and can be cued automatically by the context [92]. People are more likely to act habitually when they are depleted, distracted, or under time pressure [93].

Here, we have reviewed some challenges related to making healthy food choices. These decisions involve several important psychological factors: (1) they tend to involve a struggle between a System 1 desire and a System 2 reason to resist it, (2) the costs and benefits of each option are temporally dissociated and future costs are underweighted, (3) they require self-control, and (4) they are often habitual and bypass System 2 processing. We next turn to the 4Ps Framework for Behavior Change to address some of these challenges.

\section{The 4Ps Framework for Behavior Change}

We introduce the 4Ps Framework for Behavior Change as a broad strategy for nudging behavior toward desirable outcomes in specific situations - such as making healthy food choices. Whereas the rich and growing nudge literature offers a cornucopia of unrelated manipulations for effecting behavioral change, the 4Ps-Possibilities, Process, Persuasion, and Person - bring this research together in a framework to facilitate new ideas for both researchers and policy makers. The nudges fall into four broad categories: what choices are offered (Possibilities), how choices are made (Process), how choices are communicated (Persuasion), and how intentions are reinforced (Person). (See Fig. 1 for a summary of the framework.) Below, we discuss the 4Ps and present examples of research findings and types of interventions that fall into each.

\subsection{Possibilities}

"Possibilities" refers to the available options, or composition of the choice set, including the assortment that is offered (items and attributes), how much is offered (quantity), the arrangement (variety and bundles), and changes in the assortment over time. Interventions within Possibilities nudge people toward healthy choices either by making specific options healthier, or by changing the relative attractiveness of the options to advantage healthier ones.

Research shows that mere availability has a strong impact on consumption: people tend to eat whatever is in front of them. In a study of children's eating habits, availability was the number one driver of consumption of fresh fruits and vegetables [9]. The consumption of convenience foods such as crackers, granola bars, and juice similarly increases when families stockpile them, making those foods more available
[8]. In the domain of assortments, one study found that people are more likely to choose a healthy option (a fruit over a cookie) from a larger assortment than a smaller one [64]. Sometimes, options that are already available can be made healthier (e.g., switching from white to whole-grain pasta), or more appealing. In one study, placing fruit in a nice bowl or under a light increased fruit sales by over $100 \%$ [84].

After the choice set has been determined, the planner must decide how much of each item to offer-how large should the package or portion be? Quantity discounts (supersized pricing) can increase the amount consumed [23], due to a "unit bias" [19]: people tend to believe the appropriate amount to eat is an entire portion (e.g., plate, bowl, or package). As a result, they serve themselves more and eat more when dishes or utensils are large. In one experiment, nutrition academics at an ice cream social served themselves $31 \%$ more ice cream when given larger bowls and $57 \%$ more when given both larger bowls and larger serving spoons [88]. People also pour and drink more from short, wide glasses than tall, thin ones: children poured $70 \%$ more juice, and experienced bartenders poured $37 \%$ more alcohol into a short, wide glass of the same volume as a tall, thin one [87].

Not only the options themselves, but also the variety of an assortment impacts the attractiveness of different options, and in turn, their consumption [27]. While people are more likely to choose a healthy option when there is greater variety of them [64], even mere perceptions of variety affect satiation. People satiate faster if a meal has less variety or if they perceive a consumption experience as less varied [18]. Kahn and Wansink [34] found people ate fewer M\&Ms when a bowl contained fewer colors of them, even though all colors of M\&Ms have the same flavor.

In many cases, healthy and unhealthy options may be consumed simultaneously, and creative bundling can nudge people toward health. Bundling a healthy salad with a small portion of fries to create a "vice-virtue" bundle can persuade some people who would have ordered fries instead of salad to choose a bundle of one fourth fries and three fourths salad [43]. Vice-virtue bundles have nudged people to exercise as well-in a field study, Milkman et al. [52] encouraged people to exercise more by allowing them to listen to tempting audiobooks only while at the gym.

We have shared a number of possibilities for steering people toward healthy choices by modifying the composition of the assortment itself. Once a planner selects the assortment, he or she can then decide how to structure the choice, or how to position the possibilities in physical space. These decisions impact the choice process, to which we turn next.

\subsection{Process}

Process interventions influence behavior through changing the position of options in physical or psychological space, 


\section{POSSIBILITIES}

What choices are offered?

- Assortment

- Quantity

- Bundles

\section{PROCESS}

How are choices made?

- Accessibility

- Order

- Defaults
PERSUASION

How are choices communicated?

- Vividness

- Comparisons

- Moments of Truth
PERSON

How are intentions reinforced?

- Goals

- Habits

o Precommitment

Fig. 1 The 4Ps Framework for Behavior Change

affecting the items' relative appeal or relative ease of selection. Process interventions can change the physical location of the options (accessibility and order) or the structure of the choice (defaults). Because they involve changes to the context in which a person makes a choice, behavioral economists call Process interventions "choice architecture" [76].

Accessibility, or convenience, exerts a gentle yet powerful influence on choices. A long-term field study in a hospital cafeteria showed that making water more accessible by placing it at eye-level in refrigerators and in five baskets located near food stations increased water consumption by $26 \%$ [77]. People also drink more water when it is easily accessible on their table, rather than $20 \mathrm{ft}$ away [11]. Conversely, cafeteria visitors purchased fewer junk foods when they were less accessible, requiring waiting in a separate line [50], and in another study, people were less likely to serve themselves ice cream when it was less accessible, in a closed rather than an open freezer [41].

Order, too influences choice outcomes. Different positions are privileged in different contexts, but overall, privilege is determined by ease: choice shares are higher for options which are easiest to reach, remember, see, or rationalize. At a conference breakfast, the same seven dishes were served in two buffet lines, ordered either from healthiest to least healthy or vice-versa. Conference participants randomly assigned to one of the two lines filled two thirds of their plate with the first three dishes. As a result, those who reached the healthy items first served themselves more fruit and yogurt - and less cheesy eggs, bacon, and fried potatoes [83]. Similarly, children in a school cafeteria took more vegetables when the vegetables were placed at the front of the line [84]. Being first on a list helps too: featuring healthier sandwiches prominently on the first page of a menu can increase choice share [91]. In a set of three options, the middle item holds the privileged spot. When options are ordered by an alignable attribute such as size, people with weak preferences tend to compromise by choosing the middle option because it is easier to rationalize [66].

A final technique for influencing the choice process is through defaults [32]. Due to the powerful and pervasive bias toward the status quo [60], defaults have proven extremely effective in guiding choices even in domains as weighty as organ donations [31] and retirement savings [75], as well as food choices. In one study at a Chinese takeout restaurant, patrons were asked whether they would prefer a half-serving of rice (thereby cutting 200 cal out of their meal) without receiving a price discount. A quarter of all customers chose this option, which had always been available, but had not occurred to them when the $400 \mathrm{cal}$ serving of rice was offered as the implicit default [63]. However, defaults are less 
effective when preferences are strong. When preschool children were provided apple slices as the default side but allowed to switch to French fries, their strong preference for fries led the vast majority to reject the default apples [33].

In addition to improving the possibilities and the choice process, there are many opportunities for nudging people toward healthy choices through persuasive communication. We next turn to interventions in this domain-Persuasion.

\subsection{Persuasion}

Interventions through Persuasion change behavior by providing information and persuasive messages, as well as relying on social norms. Persuasive messaging covers what information is presented, how it is framed and communicated, at what moment it is presented, and who delivers the message. Persuasion interventions include visuals, descriptors, and "moments of truth."

Persuasion through visual images targets System 1, and can make healthy options more tempting, or unhealthy items aversive. For example, viewing a vial of fat from a gallon of whole milk stimulated a disgust response, motivating a switch to skim [25]. Simple visual classification systems provide a heuristic System 1 can easily apply. Thorndike et al. [77] found that a simple green/yellow/red (traffic light) colorcoding scheme increased the sales of healthy items (green) and reduced sales of unhealthy items (red) in a large hospital cafeteria.

Names can speak to the intuitive system as well. Researchers have found that using vivid adjectives such as "succulent" or "homemade" makes foods more appealing, tastier, and even more filling [81]. In a national Healthy Lunchrooms initiative, vivid names such as "Florida Fresh Oranges" increased fruit consumption in school cafeterias by $26 \%$ [33]. Naming also impacts a meal's perceived healthfulness, and hence the amount that people eat. People tend to eat more pasta salad when it is called the "salad special" than the "pasta special" [28]. Similarly, people eat more when portions are called "small" or "medium"-although they believe they have eaten less [2].

Successful persuasive communication requires sending the right message at the time when the individual will be most receptive to it. Although an individual pursues many goals, only a small number are active in any particular moment [15]. Planners can time persuasive messages to coincide with "moments of truth" in which the relevant goals are salient, or they can try to cue the relevant goals. A planner wishing to remind people to take the stairs might place signs next to or on the elevators, when people are thinking about their goal of getting upstairs. Stair prompts with messages such as "Burn calories, not electricity" have been found to be highly effective, increasing stair use by as much as $40 \%$, even 9 months later [40]. A planner intending to cue a goal such as dieting must be careful what stimuli they use, since some will cue differing, even opposite responses across people with differing goals. One study found that exposing dieters to images of diet foods instead of non-food images successfully reduced subsequent snack consumption, presumably because these images made their diet goal salient. However, the same images increased snack consumption among non-dieters, presumably because seeing pictures of food cued the desire and goal to eat [7].

\subsection{Person}

Interventions in the Person category shift the focus from the individual decision in a particular context to helping decision makers make better choices across contexts. Most attempts to change people's general behavior are purely informative, offering advice [78]. However, we have already discussed why in the case of food decisions, intentions and actions are not always consistent - primarily because resisting temptation requires resources such as attention and willpower, which are often in short supply. Fortunately, there are a few simple ways to support healthy intentions, relying less on System 2 processing and willpower. The specific routes we suggest for influencing a person to help them make healthy choices are goals, habits, and precommitment.

Setting explicit goals can increase healthy choices by reducing the thinking required for engaging in a healthy behavior. Effective goals are motivational and measurable - challenging, specific, and concrete [44]. For example, a concrete goal to lose $10 \mathrm{lb}$ in 5 months or to run $3 \mathrm{mi}$ three times a week for the next 5 months would be more effective than a general goal to "lose weight," where progress is not measurable and there is a lack of feedback. In addition, goals are more manageable and effective when they are broken into smaller steps. Tracking small wins along the way builds momentum: feeling progress towards a goal is motivating [39].

While setting goals and tracking progress encourages healthier behavior by appealing to intrinsic motivation, planners can also encourage healthy behavior through extrinsic motivation, or incentives. Incentives shift the relative balance of costs and benefits toward a desired option, and in some cases, the behavior continues habitually even after the incentive period has ended. Paying participants to regularly go to the gym boosted gym attendance even after the monetary incentive was removed [21], and paying people to quit smoking has been shown to be effective as well [20]. Promotions such as loyalty cards can be particularly effective because they link the financial incentive with a sense of progress towards a goal, combining extrinsic and intrinsic motivation [3].

Unlike goals, which require conscious focus and effort to stick to them, a habit is a behavior that is initiated effortlessly and automatically, triggered by a relevant cue in the 
environment [92]. Habits have become automatic over time through repetition, and they can be modified by changing environments or cues [78]. Research shows that environmental cues are extremely powerful in shaping habits, and in many cases, environmental cues trigger unhealthy food habits. For example, entering a movie theater can cue a mindless popcorn consumption habit. In one study [54], habitual popcorn eaters consumed just as much popcorn while watching a movie if the popcorn was stale as if it was fresh (despite complaining about it), while non-habitual eaters ate less when the popcorn was stale.

Given that habits are cued by the environment with minimal decision making, successful interventions involve disrupting those environmental factors. Behavior can be modified by changing environments or cues [78], although overcoming habits is hard. Eradicating poor habits is most effective when people change their environment: while traveling, after a move, or in periods of change or restructuring [78].

A final way to encourage people to make healthy choices is through precommitment—committing to a future course of action. Precommitment works by reducing reliance on willpower, allowing people to choose for the future when they are in a "cold state" rather than choosing for the present, in a "hot state" [45]. A commitment device commits a person to a future course of action, preventing or penalizing divergence from it. In an elementary school field study, children who preordered their lunch entrée were nearly twice as likely (29 vs. $15 \%$ ) to choose the healthier option [22].

Another form of precommitment, "temptation bundling," allows people to restrict their use of a tempting option (e.g., listening to enjoyable audiobooks) to coincide only with their engaging in a virtuous behavior (e.g., exercise) [52]. In one large field study using a penalizing precommitment, more than a third of grocery store customers chose to risk losing money when they precommitted to increasing their purchase share of healthy items [62] — and they subsequently purchased a greater share of healthy foods than did a control group who had made the same choice hypothetically. People are even willing to pay money for commitment devices: smokers pay a premium to buy smaller packs of cigarettes to ration their smoking [89].

We have considered different angles through which planners can impact the individual decision maker: both internal and external motivation to set goals, ways to gradually change habits, as well as commitment devices that decision makers can use to better adhere to their goals. These three approaches have potentially high payoffs because, by influencing people's patterns of behavior, they produce a long-term impact. Interventions focusing on the person can build healthy patterns of behavior over time, which can sometimes lead to these positive behaviors becoming habitual.

In this section we have introduced a novel unifying framework - the 4Ps Framework for Behavior Change - that serves as a useful way to organize research findings in psychology, behavioral economics, and marketing in order to stimulate new ideas among researchers and to help planners make healthy choices easier. In the next section, we discuss some challenges for future research on encouraging healthy behavior as well as some fruitful areas for future research.

\section{Practical Challenges for Behavior Change Research}

Conducting behavior change research is extremely important because it has the potential to create real-world positive changes in human health. While some of the nudges we reviewed above may seem insignificant, they can have profound effects when aggregated over time. One estimate shows that obesity in the majority of the population could be addressed if people ate several fewer bites at each meal or took approximately 2,000 extra steps each day [26]. While researchers striving to change behavior are committed to impacting real life outcomes, fulfilling this goal, and documenting success, provides additional challenges beyond the hurdles of the publication process. Whereas publication of research findings requires observed effects to be statistically significant, it does not require them to be of meaningful size or duration, or easily replicable. And researchers in both behavioral economics and health can help each other to address these practical challenges.

\subsection{What Constitutes a Meaningful Effect?}

Research publications favor statistically significant results, with differences large enough — and often only large enough - to imply a high likelihood of observing a measurable difference under similar circumstances in the future [69]. Aside from the "file drawer" problem that reduces the overall replicability of published results $[57,68]$, the emphasis on statistical significance detracts from meaningful impact. Since $p$ values are a function of sample size, very large samples can detect statistically significant differences of no practical import [6]. Conversely, some effect sizes technically categorized as "small" can have large practical value. For example, McCartney and Rosenthal [49] showed the impact of an educational intervention with a small effect of $r=0.14$ yielded a $700 \%$ return on investment.

When determining what will constitute a meaningful effect, indirect as well as direct outcomes should be considered. This assessment should include the balance between potential costs and benefits as well as the degree to which the outcomes of the manipulation affect the true outcomes of interest, as well as the size of the effect relative to other interventions. For example, taking one extra flight of stairs per day burns $5 \mathrm{cal}$ for a $150 \mathrm{lb}$ person, while switching one $12 \mathrm{oz}$ cola from regular to diet saves $140 \mathrm{cal}$ ( 28 flights of stairs). So if caloric intake is 
the indirect variable of interest, a successful intervention leading soda drinkers to switch to diet drinks will be more meaningful than a successful intervention leading elevator takers to switch to stairs.

Two further complications in the achievement of a meaningful change, specific to food choices, are the uncertainty around whether eating more healthy foods is actually healthy, and the uncertainty regarding which foods are healthy. In our discussion of the 4Ps Framework, we described multiple ways to increase consumption of healthy foods, starting with making more of them available more often. However, we caution that in most cases, increasing the consumption of healthy foods provides a net benefit only if it coincides with reducing the consumption of unhealthy foods. If eating more healthy foods simply means eating more, that "healthy" behavior could ironically result in weight gain, obesity, and poor health. This brings us to our next point, which is that definition of "healthy" is relative and context-dependent. We have avoided defining what a healthy food is for this reason. From a practical perspective, we suggest that both researchers and planners prioritize nudges that either decrease the consumption of foods and drinks widely believed to be unhealthy, or force tradeoffs between healthier and less healthy foods. For those seeking to quantify health differences among various foods, researchers have consulted expert opinions to develop an algorithm for calculating healthfulness based on nutritional content [48].

\subsection{How Should Impact be Measured?}

A problematic assumption in many experiments involving healthy food choices is that participants do not compensate for their healthy choices by making unhealthy ones on some other occasion. Most lab experiments measure effects in just one shot, and most field experiments measure few or only one consumption variable (e.g., potato chips). A few researchers have attempted to measure compensatory consumption. For example, nudging cafeteria customers away from candy increased their consumption of desserts and fruit, while nudging them away from potato chips increased consumption of other starches [50]. However, even these laudable experiments are unable to confirm or deny compensatory consumption in other contexts. While one solution would be to measure meaningful consequences that lie further downstream-e.g., weight or blood pressure, these outcomes have so many antecedents that detecting a meaningful effect through the noise could require unfeasibly large sample sizes. To mitigate these problems, food researchers could have a sample of participants track their overall consumption through food diaries (which may be biased overall, but could be used to show trends), or track meal and snack consumption in one location in aggregate by measuring the amount of food produced and wasted over the course of several weeks or months to observe any consistent changes in the population as a whole.

\subsection{Which Effects Persist Over Time?}

Since most "nudge" research documents impact of an intervention at one moment in time or during one time period, researchers generally cannot say whether their observed effects fade or disappear over time, and if they do, how long a meaningful effect persists. A strong test is whether interventions form habits that persist even after the context changes. Some follow-up studies failing to find a long-term impact of an incentive after it has been removed suggest that habit formation is probably the exception rather than the rule (e.g., $[30,79])$. A weak test is whether the observed behavior continues in the same environment. A few field studies have measured the effect of nudges over time-for example, fruit consumption continued throughout an entire semester at double the previous rate when it was kept in the same attractive location [84]. The duration of most nudge effects, however, has not been tested. One obvious reason is that follow-ups are difficult, costly, and sometimes impossible. However, another more insidious reason may be that researchers might sometimes prefer ignorance to risking the knowledge that their observed effects change turn out to be evanescent. For our research to be practically helpful, we must make more efforts to test long-term effects when we can, and to help practitioners test them with or without our participation.

It is particularly important to conduct research with followup measurements because psychological theories rarely predict how behavior may change over time. Changes in behavior from informational interventions that rely on attention and conscious processing - for example, those requiring that people pay attention to new labels - will likely wear off more quickly as the novelty of the labels wears off and people no longer attend to them. On the other hand, environmental interventions that are mindless, such as placing healthy options first or switching to smaller plates, may bypass conscious processing and may be less likely to wear off over time.

\subsection{Which Manipulations are Still Effective When Noticed?}

A common feature of most nudges reported here is that they operate below the level of conscious awareness, and it is sometimes assumed that success depends on concealment. However, as far as we are aware, this assumption has not yet been tested. Calling attention to an intervention precludes mindless benefits, yet it could also prime relevant goals, making them more salient and more likely to be acted upon. For example, Thorndike et al. [77] found that placing extra bins of water bottles near the cash register in a cafeteria increased water purchases. We cannot know whether the observed effect might have been larger or smaller if these bins 
had displayed a sign such as, "We stocked these bins with water to help you drink more water"-an empirical question. It is possible, too, that drawing attention to various nudges might have differing effects depending on the person and the goal. For example, most people might believe it would be a good idea for them to drink more water. But a sign on the same water bin reading "We stocked these bins with water to help you reduce your consumption of sugary beverages and lose weight" could spur reactance and might even lead some people to purchase sugary beverages out of spite for what they experience as paternalistic interference. Studies have shown that prohibition of certain foods can increase consumption of the "forbidden fruit" $[29,90]$ or decrease consumption of a mandatory healthy option [46].

We hope that more researchers studying health behavior change, and behavioral economics in general, will continue to push the envelope in conducting studies with practical impact. We do not claim to have solved these problems in our own research; we face all the same challenges other researchers do. We do, however, believe our field has great, untapped potential for benefiting health and changing behaviors outside the lab, and that we can all do a bit to nudge both field and practice forward.

\section{Conclusion}

People's behaviors do not always match their stated preferences, and diverge in predictable ways. For example, although most people report a desire to eat healthfully, their repeated failures to act consistently with this preference have contributed to an obesity epidemic. These failures to eat healthfully are predictable because they spring from multiple ways in which System 2 reasoning is hijacked by the intuitive System 1, leading people to fall prey to temptation or act without thinking. Here, we have provided some psychological explanations for these failures, and we have presented a new framework, the 4Ps Behavior Change Framework, to offer some solutions. The 4Ps Framework organizes research on making the healthy choice the easy choice, through interventions in the domains of Possibilities, Process, Persuasion, and Person. Finally, we have presented some of the practical challenges facing researchers who desire to change eating behaviors for the better, to help people align their actions with their stated healthy preferences.

\section{References}

1. Ainslie G (1975) Specious reward: a behavioral theory of impulsiveness and impulse control. Psychol Bull 82(4):463
2. Aydinoglu NZ, Aradhna K, Wansink B (2009) Do size labels have a common meaning among consumers? In: Krishna A (ed) Sensory marketing: research on the sensuality of products. Routledge, New York, pp 343-360

3. Bandura A, Cervone D (1983) Self-evaluative and self-efficacy mechanisms governing the motivational effects of goal systems. J Pers Soc Psychol 45(5): 1017

4. Bargh JA, Chartrand TL (1999) The unbearable automaticity of being. Am Psychol 54(7):462-479

5. Baumeister RF, Bratslavsky E, Muraven M, Tice DM (1998) Ego depletion: is the active self a limited resource? J Pers Soc Psychol 74(5): 1252

6. Bell ML, Olivier J, King MT (2013) Scientific rigour in psychooncology trials: why and how to avoid common statistical errors. Psycho-Oncology 22(3):499-505

7. Buckland NJ, Finlayson G, Edge R, Hetherington MM (2014) Resistance reminders: dieters reduce energy intake after exposure to diet-congruent food images compared to control non-food images. Appetite 73:189-196

8. Chandon P, Wansink B (2002) When are stockpiled products consumed faster? A convenience-salience framework of postpurchase consumption incidence and quantity. J Mark Res 39(3):321-335

9. Cullen KW, Baranowski T, Owens E, Marsh T, Rittenberry L, de Moor C (2003) Availability, accessibility, and preferences for fruit, $100 \%$ fruit juice, and vegetables influence children's dietary behavior. Health Educ Behav 30(5):615-626

10. Dhar R, Gorlin M (2013) A dual-system framework to understand preference construction processes in choice. J Consum Psychol 23(4):528-542

11. Engell D, Kramer M, Malafi T, Salomon M, Lesher L (1996) Effects of effort and social modeling on drinking in humans. Appetite 26(2): 129-138

12. Epstein S (1994) Integration of the cognitive and the psychodynamic unconscious. Am Psychol 49(8):709-724

13. Finkelstein EA, daCosta DBM, Burgess SM, Hale BC (2010) The costs of obesity in the workplace. J Occup Environ Med 52(10):971976

14. Finkelstein EA, Trogdon JG, Cohen JW, Dietz W (2009) Annual medical spending attributable to obesity: payer- and service-specific estimates. Health Aff 28(5):822-831

15. Fishbach A, Dhar R (2005) Goals as excuses or guides: the liberating effect of perceived goal progress on choice. J Consum Res 32(3): 370-377

16. Flegal KM, Graubard BI, Williamson DF, Gail MH (2007) Causespecific excess deaths associated with underweight, overweight, and obesity. JAMA 17:2028-2037

17. Frederick S, Lowenstein G, O'Donoghue T (2002) Individual discounting and time preference: a critical review. J Econ Lit 40:10

18. Galak J, Redden JP, Kruger J (2009) Variety amnesia: Recalling past variety can accelerate recovery from satiation. J Consum Res 36(4): 575-584

19. Geier AB, Rozin P, Doros G (2006) Unit bias: a new heuristic that helps explain the effect of portion size on food intake. Psychol Sci 17(6):521-525

20. Giné X, Karlan D, Zinman J (2010) Put your money where your butt is: a commitment contract for smoking cessation. Am Econ J Appl Econ 2:213-235

21. Gneezy U, Charness G (2009) Incentives to exercise. Econometrica 77(3):909-931

22. Hanks AS, Just DR, Wansink B (2013) Preordering school lunch encourages better food choices by children. JAMA Pediatr 167(7): 673-674

23. Haws KL, Winterich KP (2013) When value trumps health in a supersized world. J Mark 77(3):48-64

24. Healy M (2013) Study disputes bariatric surgery savings. Los Angeles Times 
25. Heath C, Heath D (2010) Switch: how to change things when change is hard. Random House, New York

26. Hill JO, Wyatt HR, Reed GW, Peters JC (2003) Obesity and the environment: where do we go from here? Science 299(5608):853855

27. Hoch SJ, Bradlow ET, Wansink B (1999) The variety of an assortment. Mark Sci 18(4):527-546

28. Irmak C, Vallen B, Robinson SR (2011) The impact of product name on dieters' and nondieters' food evaluations and consumption. J Consum Res 38(2):390-405

29. Jansen E, Mulkens S, Jansen A (2007) Do not eat the red food!: prohibition of snacks leads to their relatively higher consumption in children. Appetite 49(3):572-577

30. John LK, Loewenstein G, Troxel AB, Norton L, Fassbender JE, Volpp KG (2011) Financial incentives for extended weight loss: a randomized, controlled trial. J Gen Intern Med 26(6):621-626

31. Johnson EJ, Goldstein D (2003) Do defaults save lives? Science 302: 1338-39

32. Johnson EJ, Goldstein D (2004) Defaults and donation decisions. Transplantation 78(12):1713-1716

33. Just DR, Wansink B (2009) Smarter lunchrooms: using behavioral economics to improve meal selection. Choices 24(3):1-7

34. Kahn BE, Wansink B (2004) The influence of assortment structure on perceived variety and consumption quantities. J Consum Res 30(4): 519-533

35. Kahneman D, Frederick S (2002) Representativeness revisited: attribute substitution in intuitive judgment. In: Gilovich T, Griffin D, Kahneman D (eds) Heuristics of intuitive judgment: extensions and applications. Cambridge University Press, New York

36. Khan U, Dhar R (2006) Licensing effect in consumer choice. J Mark Res 43(2):259-266

37. Khan U, Dhar R (2007) Where there is a way, is there a will? The effect of future choices on self-control. J Exp Psychol Gen 136(2): 277

38. Kirby KN, Guastello B (2001) Making choices in anticipation of similar future choices can increase self-control. J Exp Psychol Appl $7(2): 154$

39. Kivetz R, Urminsky O, Zheng Y (2006) The goal-gradient hypothesis resurrected: purchase acceleration, illusionary goal progress, and customer retention. J Mark Res 43(1):39-58

40. Lee KK, Perry AS, Wolf SA, Agarwal R, Rosenblum R, Fischer S, Silver LD (2012) Promoting routine stair use: evaluating the impact of a stair prompt across buildings. Am J Prev Med 42(2):136-141

41. Levitz LS (1976) The susceptibility of human feeding behavior to external controls. Obes Perspect 53-60

42. Libet B (1993) Unconscious cerebral initiative and the role of conscious will in voluntary action. Neurophysiology of consciousness Birkhäuser, Boston, pp 269-306

43. Liu PJ, Haws KL, Lamberton C, Campbell TH, Fitzsimons GJ (2014) Vice-virtue bundles. Working Paper, Duke University, Durham, NC

44. Locke EA, Latham GP (2002) Building a practically useful theory of goal setting and task motivation: a 35-year odyssey. Am Psychol 57(9):705

45. Loewenstein G (2000) Emotions in economic theory and economic behavior. Am Econ Rev 426-432

46. Lombardini C, Lankoski L (2013) Forced choice restriction in promoting sustainable food consumption: Intended and unintended effects of the mandatory vegetarian day in Helsinki schools. J Consum Policy 36(2):159-178

47. Market Data Enterprises (2009) The Weight Loss \& Diet Control Market

48. Martin JM, Beshears J, Milkman KL, Bazerman MH, Sutherland LA (2009) Modeling expert opinions on food healthfulness: a nutrition metric. J Am Diet Assoc 109(6):1088-1091
49. McCartney K, Rosenthal R (2000) Effect size, practical importance, and social policy for children. Child Dev 71(1):173-180

50. Meiselman HL, Hedderley D, Staddon SL, Pierson BJ, Symonds CR (1994) Effect of effort on meal selection and meal acceptability in a student cafeteria. Appetite 23(1):43-55

51. Mello MM, Rosenthal MB (2008) Wellness programs and lifestyle discrimination - the legal limits. N Engl J Med 359(2):192

52. Milkman KL, Minson JA, Volpp KGM (2014) Holding the hunger games hostage at the gym: an evaluation of temptation bundling. Manag Sci 60(2):283-299

53. Milkman KL, Rogers T, Bazerman MH (2008) Harnessing our inner angels and demons: what we have learned about want/should conflicts and how that knowledge can help us reduce short-sighted decision making. Perspect Psychol Sci 3(4):324-338

54. Neal DT, Wood W, Lally P, Wu M (2009) Do habits depend on goals? Perceived versus actual role of goals in habit performance. Manuscript under review, University of Southern California

55. O'Donoghue T, Rabin M (2000) The economics of immediate gratification. J Behav Decis Mak 13(2):233-250

56. Rick S, Loewenstein G (2008) The role of emotion in economic behavior. Handbook Emotions : 138-156

57. Rosenthal R (1979) The "file drawer problem" and tolerance for null results. Psychol Bull 86:638-641

58. Ruhm CJ (2012) Understanding overeating and obesity. J Health Econ 31(6):781-796

59. Samuelson P (1938) A note on the pure theory of consumers' behavior. Economica 5(17):61-71

60. Samuelson W, Zeckhauser R (1988) Status quo bias in decision making. J Risk Uncertain 1(1):7-59

61. Schmeichel BJ (2007) Attention control, memory updating, and emotion regulation temporarily reduce the capacity for executive control. J Exp Psychol Gen 136(2):241

62. Schwartz J, Mochon D, Wyper L, Maroba J, Patel D, Ariely D (2014) Healthier by precommitment. Psychol Sci 25(2): $538-546$

63. Schwartz J, Riis J, Elbel B, Ariely D (2012) Inviting consumers to downsize fast-food portions significantly reduces calorie consumption. Health Aff 31(2):399-407

64. Sela A, Berger J, Liu W (2009) Variety, vice, and virtue: how assortment size influences option choice. J Consum Res 35(6):941951

65. Share Our Strength (2014) It's dinnertime: a report on low-income families' efforts to plan, shop for and cook healthy meals. Available online at: http://www.nokidhungry.org/images/cm-study/reporthighlights.pdf

66. Sharpe KM, Staelin R, Huber J (2008) Using extremeness aversion to fight obesity: policy implications of context dependent demand. J Consum Res 35(3):406-422

67. Shiv B, Fedorikhin A (1999) Heart and mind in conflict: the interplay of affect and cognition in consumer decision making. J Consum Res 26(3):278-292

68. Simmons JP, Nelson LD, Simonsohn U (2011) False-positive psychology: undisclosed flexibility in data collection and analysis allows presenting anything as significant. Psychol Sci 22(11):1359-1366

69. Simonsohn U, Nelson LD, Simmons JP (2014) $P$-curve: a key to the file drawer. J Exp Psychol 143(2):534-547

70. Simonson I (2005) In defense of consciousness: the role of conscious and unconscious inputs in consumer choice. J Consum Psychol 15(3):211-217

71. Sloman SA (1996) The empirical case for two systems of reasoning. Psychol Bull 119(1):3-22

72. Soon CS, Brass M, Heinze HJ, Haynes JD (2008) Unconscious determinants of free decisions in the human brain. Nat Neurosci 11(5):543-545

73. Stanovich KE (2011) Rationality and the reflective mind. Oxford University Press, New York 
74. Stanovich KE, West R (2002) Heuristics and biases: The psychology of intuitive judgment

75. Thaler RH, Benartzi S (2004) Save More Tomorrow ${ }^{\mathrm{TM}}$ : using behavioral economics to increase employee saving. J Polit Econ 112(S1): S164-S187

76. Thaler RH, Sunstein CR (2008) Nudge: improving decisions about health, wealth, and happiness. Yale University Press, New Haven, Connecticut

77. Thorndike AN, Sonnenberg L, Riis J, Barraclough S, Levy DE (2012) A 2-phase labeling and choice architecture intervention to improve healthy food and beverage choices. Am J Public Health 3:527-533

78. Verplanken B, Wood W (2006) Interventions to break and create consumer habits. J Publ Pol Mark 25(1):90-103

79. Volpp KG, Levy AG, Asch DA, Berlin JA, Murphy JJ, Gomez A, Sox H, Zhu J, Lerman C (2006) A randomized controlled trial of financial incentives for smoking cessation. Cancer Epidemiol Biomark Prev 15:12-18

80. Wang J, Novemsky N, Dhar R, Baumeister RF (2010) Trade-offs and depletion in choice. J Mark Res 47(5):910-919

81. Wansink B (2007) Mindless eating: Why we eat more than we think. Random House: New York.

82. Wansink B, Chandon P (2014) Slim by design: redirecting the accidental drivers of mindless overeating. J Consum Psychol 24(3): 413-431

83. Wansink B, Hanks AS (2013) Slim by design: serving healthy foods first in buffet lines improves overall meal selection. PLoS One 8(10): e77055
84. Wansink B, Just D, Smith L (2011) Move the fruit: putting fruit in new bowls and new places doubles lunchroom sales. J Nutr Educ Behav 43(4):S1

85. Wansink B, Painter JE, North J (2005) Bottomless bowls: why visual cues of portion size may influence intake. Obes Res 13(1):93-100

86. Wansink B, Sobel J (2007) Hidden persuaders and 200 daily decisions. Environ Behav 39(1):106-123

87. Wansink B, Van Ittersum K (2003) Bottoms up! The influence of elongation on pouring and consumption volume. J Consum Res 30(3):455-463

88. Wansink B, Van Ittersum K, Painter JE (2006) Ice cream illusions: bowls, spoons, and self-served portion sizes. Am J Prev Med 31(3): 240-243

89. Wertenbroch K (1998) Consumption self-control by rationing purchase quantities of virtue and vice. Mark Sci 17(4):317-337

90. West SG (1975) Increasing the attractiveness of college cafeteria food: a reactance theory perspective. J Appl Psychol 60(5):656

91. Wisdom J, Downs JS, Loewenstein G (2010) Promoting healthy choices: Information versus convenience. Am Econ J Appl Econ 164-178

92. Wood W, Neal DT (2007) A new look at habits and the habit-goal interface. Psychol Rev 114(4):843

93. Wood W, Neal DT (2009) The habitual consumer. J Consum Psychol 19(4):579-592

94. Wood W, Quinn JM, Kashy DA (2002) Habits in everyday life: thought, emotion, and action. J Pers Soc Psychol 83(6): 1281 